\title{
The protective effect of prone lung position on ischemia-reperfusion injury and lung function in an ex vivo porcine lung model
}

\author{
Hiromichi Niikawa, MD, PhD, ${ }^{\mathrm{a}, \mathrm{b}}$ Toshihiro Okamoto, MD, PhD, ${ }^{\mathrm{a}, \mathrm{b}, \mathrm{c}}$ Kamal S. Ayyat, MD, ${ }^{\mathrm{a}, \mathrm{b}, \mathrm{e}}$ \\ Yoshifumi Itoda, MD, PhD, ${ }^{\mathrm{a}, \mathrm{b}}$ Carol F. Farver, MD, ${ }^{\mathrm{d}}$ and Kenneth R. McCurry, MD ${ }^{\mathrm{a}, \mathrm{b}, \mathrm{c}}$
}

\section{ABSTRACT}

Objective: Prone positioning has been shown to improve oxygenation in patients with lung injury. We hypothesized that prone positioning of lungs during ex vivo lung perfusion (EVLP) can not only improve oxygenation but also diminish ischemia-reperfusion injury (IRI). The aim of our study was to evaluate the potential benefits of prone positioning of lungs during EVLP compared with the standard supine position.

Methods: Ten pigs were kept in the supine position at room temperature for 2 hours after circulatory death after which lungs were procured and subjected to 5 hours of cold storage. Lungs then underwent 2 hours of cellular EVLP with either supine positioning (Control group, $\mathrm{n}=5$ ) or prone positioning (Prone group, $\mathrm{n}=5$ ). Lung function was evaluated by assessment of physiological parameters and tissue histology and cytokines.

Results: IRI in the Prone group was significantly less than in the Control group. Lungs in the Prone group were significantly associated with greater partial pressure of oxygen/fraction of inspired oxygen ratio median (minimummaximum) (301 mm Hg [272-414 mm Hg] vs $166 \mathrm{~mm} \mathrm{Hg} \mathrm{[109-295]} \mathrm{mm} \mathrm{Hg,}$ $P=.03)$, better static compliance $\left(38.9 \mathrm{~mL} / \mathrm{cmH}_{2} \mathrm{O}\left[31.1-44.3 \mathrm{~mL} / \mathrm{cmH}_{2} \mathrm{O}\right] \mathrm{vs}\right.$ $\left.21.5 \mathrm{~mL} / \mathrm{cmH}_{2} \mathrm{O}\left[12.2-33.3 \mathrm{~mL} / \mathrm{cmH}_{2} \mathrm{O}\right], P=.03\right)$, lower lung weight ratio (1.26 [1.24-1.41] vs 1.48 [1.36-2.34], $P=.02)$, and lower interleukin- $\beta$ levels $(1.6 \mathrm{ng} / \mathrm{mL}[0.9-5.3 \mathrm{ng} / \mathrm{mL}]$ vs $7.5 \mathrm{ng} / \mathrm{mL}$ [5.0-16.1 ng/mL], $P=.04)$ compared with lungs in the Control group.

Conclusions: These data suggest that prone positioning of lungs during EVLP may diminish IRI during EVLP and improve lung function. (J Thorac Cardiovasc Surg 2019;157:425-33)

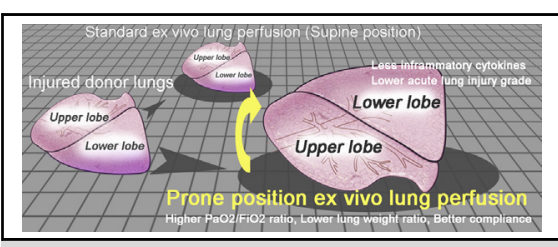

Concept figure of this study, prone position ex vivo lung perfusion vs. supine position ex vivo lung perfusion (Control)

\section{Central Message}

Prone positioning can protect donor lungs from ischemia reperfusion injury during ex vivo lung perfusion. We found better lung function and less acute lung injury in Prone than Control group.

\section{Perspective}

Prone positioning facilitates improvement of lung function in patients with severe lung injury in clinical intensive care. We investigated effect of prone positioning against ischemia reperfusion injury of donor lungs in ex vivo lung and found efficacy of prone positioning.

See Editorial Commentary page 434

See Editorial page 423.
Historically, patients have been managed in a supine position in intensive care units (ICUs). ${ }^{1}$ Evidence suggests that prone positioning significantly improves oxygenation of patients with severe lung injury. ${ }^{2}$ The benefit from prone positioning is likely improvement of oxygenation due to enhancement of

\footnotetext{
From the ${ }^{a}$ Department of Pathobiology, Lerner Research Institute, ${ }^{b}$ Department of Thoracic and Cardiovascular Surgery, ${ }^{\mathrm{c}}$ Transplant Center, and ${ }^{\mathrm{d}}$ Anatomic Pathology, Cleveland Clinic, Cleveland, Ohio; and ${ }^{\mathrm{e}}$ Department of Cardiothoracic Surgery, Faculty of Medicine, Zagazig University, Zagazig, Egypt.

Received for publication April 25, 2018; revisions received July 24, 2018; accepted for publication Aug 11, 2018; available ahead of print Nov 8, 2018

Address for reprints: Toshihiro Okamoto, MD, PhD, and Kenneth R. McCurry, MD, 9500 Euclid Ave, Cleveland, Ohio 44195 (E-mail: okamott@ccf.org or mccurrk@ ccf.org).

$0022-5223 / \$ 36.00$

Copyright (c) 2018 by The American Association for Thoracic Surgery

https://doi.org/10.1016/j.jtcvs.2018.08.101
}

ventilation/perfusion (V/Q) matching. The compressed lung tissue on the dorsal side is better expanded by position change with an increase in functional residual capacity. In addition, improvement of the bronchial drainage is likely to improve the ventilation. ${ }^{5}$ In animals, positive end-expiratory pressure and posture act synergistically by redistributing lung regional perfusion toward ventral regions but have antagonistic effects on regional ventilation. ${ }^{6}$

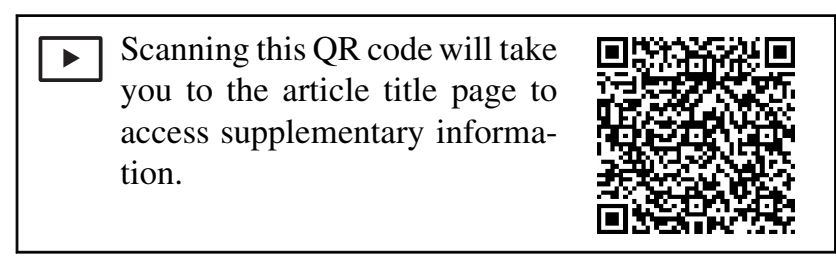




$$
\begin{aligned}
& \text { Abbreviations and Acronyms } \\
& \begin{aligned}
\mathrm{ALI} & =\text { acute lung injury } \\
\mathrm{EVLP} & =\text { ex vivo lung perfusion } \\
\mathrm{FiO}_{2} & =\text { fraction of inspired oxygen } \\
\mathrm{ICU} & =\text { intensive care unit } \\
\mathrm{IL} & =\text { interleukin } \\
\mathrm{IRI} & =\text { ischemic reperfusion injury } \\
\mathrm{PEEP} & =\text { positive end-expiratory pressure } \\
\mathrm{P} / \mathrm{F} & =\text { partial pressure of oxygen/fraction of } \\
\mathrm{TV} & =\text { inspired oxygen } \\
\mathrm{V} / \mathrm{Q} & =\text { ventilation/perfusion }
\end{aligned}
\end{aligned}
$$

Ex vivo lung perfusion (EVLP) has the significant potential to improve the donor lung shortage by recovering donor lung function after being initially rejected. ${ }^{7-10}$ EVLP can also provide an opportunity to treat rejected donor lungs before lung transplantation. Nakajima and colleagues ${ }^{11}$ showed that antimicrobial treatment for infected lungs on EVLP may improve pulmonary function and Cypel and colleagues ${ }^{12}$ have demonstrated that interleukin (IL)-10 gene therapy of rejected human donor lungs during EVLP resulted in improved lung function. Similarly, prone positioning during EVLP might improve function through enhanced V/Q matching and potentially reduce lung inflammation and injury. Although there is no report investigating the effect of prone positioning of lungs in EVLP, Chan and colleagues ${ }^{13}$ demonstrated reduction of lung inflammation in patients with acute respiratory distress syndrome treated with prone positioning.

We hypothesized that prone positioning during EVLP might improve the function of and reduce inflammation in pig lungs subjected to warm and then cold ischemia before EVLP. The aim of this study was to investigate the potential benefits of prone positioning and its cytoprotective effect using a porcine model. The overall goal of this project was to better understand the method for the therapeutic application of prone positioning in ex vivo porcine lung perfusion and to lay the foundation for future evaluation.

\section{MATERIAL AND METHODS \\ Study Design}

The study design is shown in Figure 1. Ten pigs were euthanized and lungs subjected to 2 hours of warm ischemia in situ with pigs in a supine position. Lungs were procured in a standard fashion with cold flush and subjected to 5 hours of cold static storage. Lungs were subsequently perfused for 2 hours using cellular EVLP with a protocol consisting of open left atrium, circuit flow of $70 \mathrm{~mL} / \mathrm{kg}$ ideal body weight/minute, positive end-expiratory pressure (PEEP) 5, and tidal volume (TV) $6 \mathrm{~mL} / \mathrm{kg}$ ideal body weight. After cold storage, pairs of pig lungs were alternately placed in 2 groups: the Control group $(n=5)$, which underwent EVLP in a standard supine position, and the Prone group $(\mathrm{n}=5)$, which underwent EVLP with lungs in a prone position (as shown in Figure 2). As detailed herein, lungs were evaluated with physiologic parameters, assessment of gas exchange, tissue biopsies, and tissue cytokine levels at various timepoints. More detailed information is provided in Video 1.

\section{Animal Preparation and Lung Procurement}

Female Yorkshire pigs (50-70 kg) were anesthetized according to the Cleveland Clinic Institutional Animal Care and Use Committee guidelines. All pigs were sedated with ketamine/xylazine $(20 \mathrm{mg} / 2 \mathrm{mg} / \mathrm{kg}$ intravenously) followed by intubation and general anesthesia with isoflurane (1.0\%-2.0\%). Pigs were administered 500 units $/ \mathrm{kg}$ heparin intravenously and after 3 minutes were killed by an intravenous injection of potassium chloride $(2.0 \mathrm{mEq} / \mathrm{kg})$. After death, the endotracheal tube was disconnected from the ventilator and kept open to the atmosphere. We worked to produce moderate atelectasis in the dependent region of the lower lobe for the 2 hours of warm ischemia in the supine position. Pigs were kept in a supine position for 2 hours, after which lungs were procured in a standard fashion as previously described. ${ }^{14,15}$ In brief, lungs were flushed with 1 liter of $4^{\circ} \mathrm{C}$ PERFADEX (XVIVO Perfusion Inc., Englewood, CO), the trachea clamped with lungs at $50 \%$ of total lung capacity, and the lungs explanted then stored for 5 hours in $4^{\circ} \mathrm{C}$ PERFADEX before EVLP. The combination of 2 hours of warm ischemia and 5 hours of cold ischemia could cause significant ischemia reperfusion injury after 2 hours of cellular EVLP, as we have reported. ${ }^{14,16}$

\section{Ex Vivo Lung Perfusion}

The EVLP system used was the Vivoline LS1 (Vivoline Medical AB, Lund, Sweden), which consists of a roller pump, a reservoir, a membrane oxygenator, a heat exchanger, and a leukocyte filter. The system was primed with $2.0 \mathrm{~L}$ of STEEN solution, heparin 10,000 IU, and 2 units of packed red blood cells resulting in a hematocrit of $10 \%$ to $15 \%$. The $\mathrm{pH}$ was corrected to between 7.35 and 7.45 with isotonic trometamol. Imipenem $100 \mathrm{mg}$ was added to the perfusate. The left atrium was left open and a temperature probe was sutured inside the left atrium. Perfusion was started at 0.2 to $0.3 \mathrm{~L} / \mathrm{min}$, and the lungs were gradually warmed to a target of $37^{\circ} \mathrm{C}$. The flow rate was increased gradually to a target level of $70 \mathrm{~mL} / \mathrm{min}$ per kilogram pig weight and the pulmonary artery pressure was kept less than $20 \mathrm{~mm} \mathrm{Hg}$. When the temperature reached $32^{\circ} \mathrm{C}$, mechanical volume-controlled ventilation (Servo-i; Maquet Critical Care, Solna, Sweden) was started using initial ventilation settings of TV 2-3 mL/kg, respiratory rate 7, PEEP 5, and fraction of inspired oxygen $\left(\mathrm{FiO}_{2}\right)$ 0.4. When the lung temperature reached $37^{\circ} \mathrm{C}$ after 30 to 40 minutes of perfusion, ventilator settings were adjusted to TV $6 \mathrm{~mL} / \mathrm{kg}$, respiratory rate 7, PEEP 5, and $\mathrm{FiO}_{2}$ 0.4. Perfusion was continued for 2 hours.

\section{Blood Preparation for EVLP}

Whole blood was obtained from dedicated blood donor pigs. Whole blood was washed in a cell saver and stored in Terumo (Lakewood, Colo) blood bags at $4^{\circ} \mathrm{C}$ before it was used for EVLP.

\section{Lung Function Assessment on EVLP}

Blood gas analysis was performed on blood obtained synchronously from lower-lobe pulmonary veins, upper lobe pulmonary veins, and left atrial blood (a mixture of upper and lower lobe blood) to assess gas exchange. Blood gas analysis was performed at 2 hours of EVLP at $\mathrm{FiO}_{2}$ 1.0. Pulmonary mechanics (peak airway pressure, plateau pressure, and mean airway pressure) and pulmonary artery pressure were recorded at 1 and 2 hours. Pulmonary artery resistance was calculated as $80 \times(\mathrm{PAP}-\mathrm{LAP}) /$ circuit flow, where PAP $=$ mean pulmonary artery pressure and LAP $=$ left atrial pressure (assumed 0 with open left atrium), and static compliance was calculated as TV/plateau pressure-PEEP.

\section{LUNG TISSUE SAMPLE COLLECTION}

Lung tissue samples were obtained from the upper and lower lobes at 0 and 2 hours of EVLP. To avoid differences in gravitational effect on the ventral side and the dorsal side, 


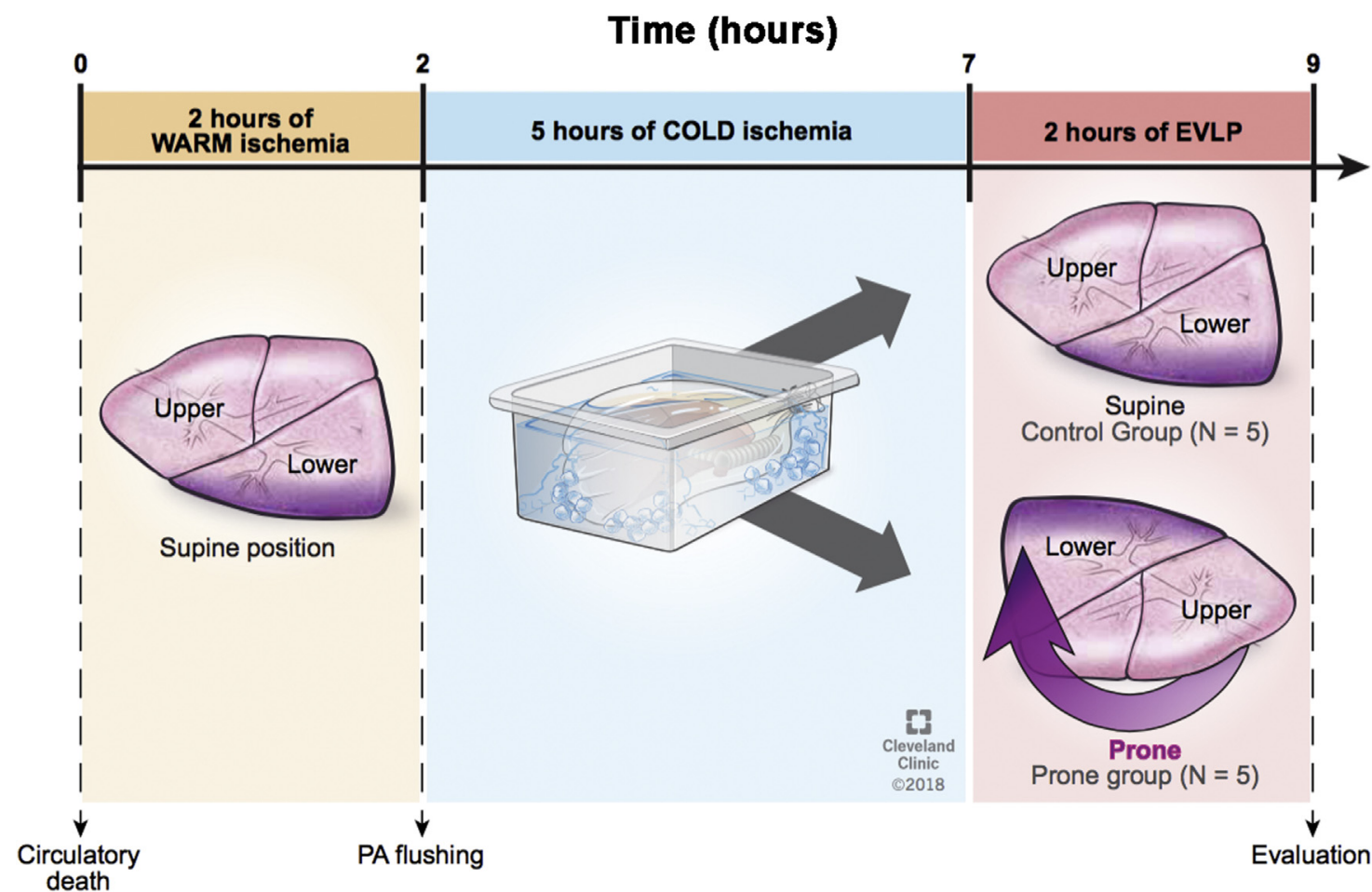

FIGURE 1. Study design: lungs were subjected to 2 hours of warm ischemia with pigs in a supine position. Lungs were procured in a standard fashion with cold flush and subjected to 5 hours of cold static storage. Lungs were subsequently perfused for 2 hours using cellular EVLP with a protocol consisting of open left atrium, circuit flow of $70 \mathrm{~mL} / \mathrm{kg}$ ideal body weight/minute, PEEP 5 , and tidal volume $6 \mathrm{~mL} / \mathrm{kg}$ ideal body weight. Pig lung pairs were divided into 2 groups: Control group $(\mathrm{N}=5)$, which underwent EVLP in a standard supine position, and the Prone group $(\mathrm{N}=5)$, which underwent EVLP with lungs in the prone position. Lungs were evaluated with physiologic parameters, assessment of gas exchange, tissue biopsies, and tissue cytokine levels at various timepoints. EVLP, Ex vivo lung perfusion; $P A$, pulmonary artery.

lung samples were taken from the central region of the upper and lower lobes in both groups. Portions were used for cytokine analysis, portions frozen in liquid nitrogen, and stored at $-80^{\circ} \mathrm{C}$ and portions fixed in formalin.
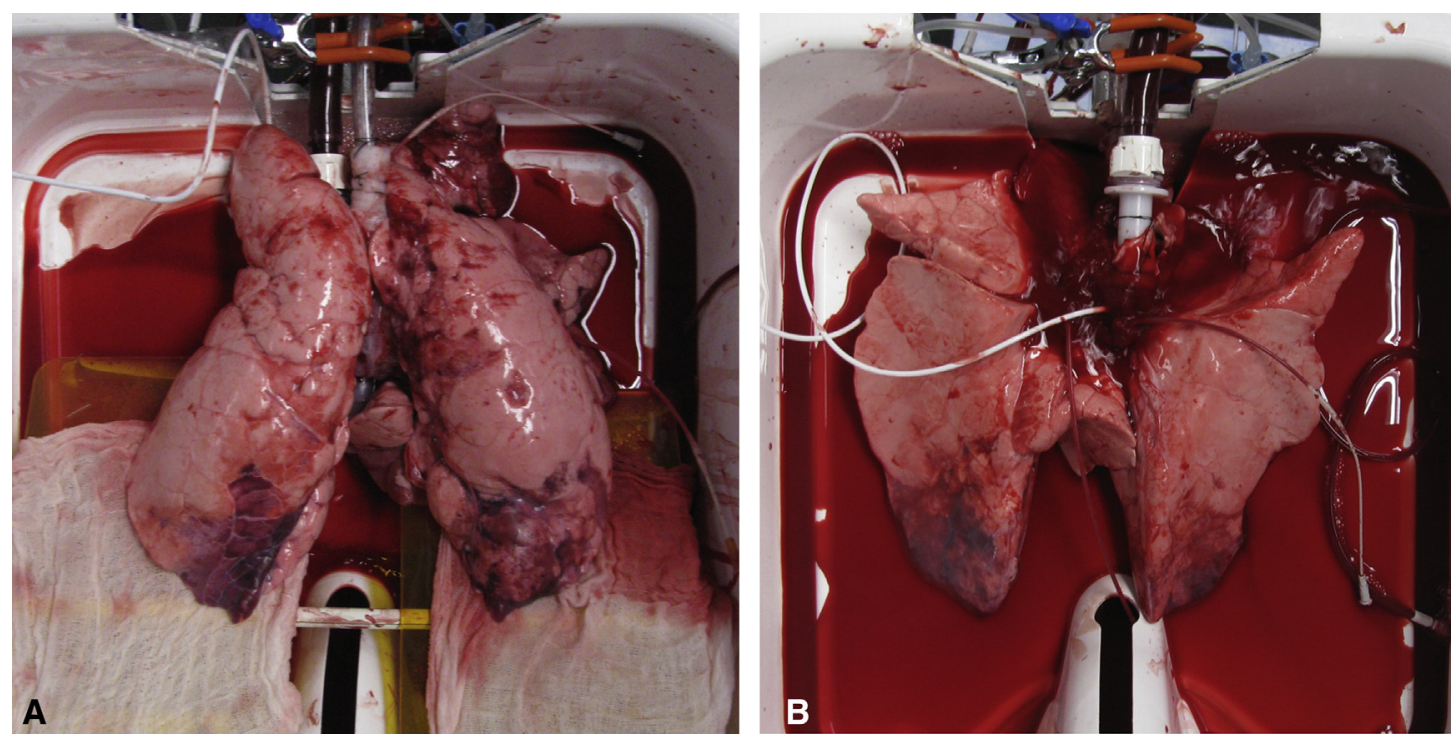

FIGURE 2. A, Image of the lungs in the prone position during EVLP (Prone group). B, Image of the lungs in the supine position during EVLP (Control group). EVLP, Ex vivo lung perfusion. 


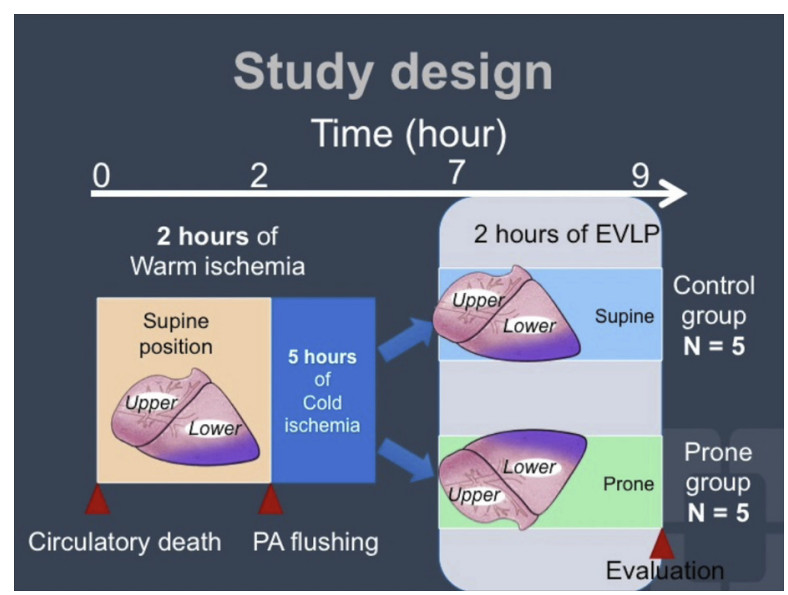

VIDEO 1. Dr Niikawa and Dr Ayyat provide a brief introduction and the most important findings of this study. The video also emphasizes the most important features of this manuscript with slides from The American Association for Thoracic Surgery 2018 oral presentation. Video available at: https://www.jtcvs.org/article/S0022-5223(18)32496-6/fulltext.

\section{Tissue Cytokine Analysis}

Homogenated lung tissue samples were evaluated in duplicate for three cytokines (IL-1 $\beta$, IL-8, and IL-10) at 0 and 2 hours of EVLP. Cytokine analysis was performed in multiplex using the Luminex Platform (R\&D Systems, Inc, Minneapolis, Minn). Samples were compared with their individual curves based upon the linear range defined by the standards and the low- and high-quality controls. Samples were only considered with correlation coefficients below $20 \%$, and all evaluations were done using 100 events of analysis.

\section{Monitoring of Lung Surface Temperature}

Infrec Thermo Gear G100 (Nippon Avionics Co, Ltd, Tokyo, Japan) thermography was used to detect lung surface temperature. Lung surface temperature was measured at 0 and 2 hours of EVLP.

\section{Histopathology Analysis}

Formalin-fixed, paraffin-embedded lung tissue was sectioned at $5 \mu \mathrm{m}$ and stained with hematoxylin and eosin. Acute lung injury (ALI) grade was assessed in a blinded fashion by C.F. To summarize, ALI grades of 0 to 3 were used to represent the severity and the extent of ALI, with 0 standing for no visible evidence and 3 for maximum severity and complete involvement. We calculated the difference of ALI grade as well. ALI grade difference was defined as follows: ALI grade difference $=$ ALI grade at 2 hours-ALI grade at 0 hours.

\section{Statistical Analysis}

All statistical analyses were performed using JMP, Version 13.1.0 (SAS Institute Inc, Cary, NC). All parameters were expressed as a median and a range (minimum-maximum). Repeated analysis of nonparametric Wilcoxon signed rank tests was used to analyze the differences in numeric data between groups, and a Fisher exact test was used for categorical data. $P<.05$ was considered significant.

\section{RESULTS}

\section{Donor Characteristics}

Donor characteristics are demonstrated in Table 1. No significant difference was found between the 2 groups in body weight $(49.0 \mathrm{~kg}$ [46.0-51.6 kg] vs $52.1 \mathrm{~kg}$ [45.8-59.0 kg], $P=.40)$, lung weight at 0 hours $(457 \mathrm{~g}$ $[379-797 \mathrm{~g}]$ vs $532 \mathrm{~g}$ [480-689 g], $P=.21$ ), the percentage of lower lobe atelectasis $(30.0 \%[5.0 \%-40.0 \%]$ vs $30.0 \%[20.0 \%-35.0 \%], P=.91)$, and body temperature at opening chest $\left(34.3^{\circ} \mathrm{C}\left[32.8^{\circ} \mathrm{C}-36.8^{\circ} \mathrm{C}\right]\right.$ vs $36.5^{\circ} \mathrm{C}$ $\left.\left[32.9^{\circ} \mathrm{C}-39.0^{\circ} \mathrm{C}\right], P=.27\right)$. Body temperatures, at the time of opening the chest, were obtained in 4 of 5 cases in the Control group due to the nonavailability of the thermometer.

\section{Lung Evaluation on EVLP}

Physiological parameters and blood gas analysis data at 2 hours EVLP are shown in Table 2. The partial pressure of oxygen/fraction of inspired oxygen $(\mathrm{P} / \mathrm{F})$ ratio in the left atrium blood in the Prone group was significantly greater than that in the Control group $(301 \mathrm{~mm} \mathrm{Hg}$ [272-414 mm Hg] vs $166 \mathrm{~mm} \mathrm{Hg}$ [109-295 mm Hg], $P=.04)$. Notably, the $\mathrm{P} / \mathrm{F}$ ratio in the lower lobe pulmonary vein blood in the Prone group was significantly greater than that in the Control group ( $424 \mathrm{~mm} \mathrm{Hg}$ [278-466 mm Hg] vs $59 \mathrm{~mm} \mathrm{Hg}$ [43-259 $\mathrm{mm} \mathrm{Hg}], P=.01$ ), whereas the $\mathrm{P} / \mathrm{F}$ ratio

TABLE 1. Donor characteristics

\begin{tabular}{|c|c|c|c|}
\hline Variables & Control group median (minimum-maximum) & Prone group median (minimum-maximum) & $P$ value \\
\hline $\mathrm{N}$ & 5 & 5 & \\
\hline Body weight, kg & $49.0(46.0-51.6)$ & $52.1(45.8-59.0)$ & .40 \\
\hline Lung weight at 0 hours, $g$ & $457(379-797)$ & $532(480-689)$ & .21 \\
\hline Atelectasis, $\%$ & $30.0(5.0-40.0)$ & $30.0(20.0-35.0)$ & .91 \\
\hline Body temperature, ${ }^{\circ} \mathrm{C}^{*}$ & $34.3(32.8-36.8)$ & $36.5(32.9-39.0)$ & .27 \\
\hline
\end{tabular}

Nonparametric Wilcoxon signed rank tests were performed to compare the 2 groups. *Body temperatures were obtained in 4 of 5 cases in the Control group due to logistics. We could not measure body temperature in 1 experiment due to the nonavailability of the thermometer. 
TABLE 2. EVLP parameters at 2 hours

\begin{tabular}{|c|c|c|c|}
\hline Variables & $\begin{array}{l}\text { Control group median } \\
\text { (minimum-maximum) }\end{array}$ & $\begin{array}{l}\text { Prone group median } \\
\text { (minimum-maximum) }\end{array}$ & $P$ value \\
\hline $\mathrm{N}$ & 5 & 5 & \\
\hline Lung weight at 2 hours, $g$ & $808(515-1177)$ & $659(601-972)$ & .40 \\
\hline Lung weight ratio & $1.48(1.36-2.34)$ & $1.26(1.24-1.41)$ & .02 \\
\hline \multicolumn{4}{|l|}{$\mathrm{ABG}$ on left atrium } \\
\hline $\mathrm{P} / \mathrm{F}$ ratio, $\mathrm{mm} \mathrm{Hg}$ & $301(272-414)$ & $166(109-295)$ & .03 \\
\hline Shunt fraction, $\%$ & $51.4(39.6-60.1)$ & $36.7(25.2-38.9)$ & .01 \\
\hline A-a gradient, $\mathrm{mmHg}$ & $499.1(374.3-556.4)$ & $368.1(249.8-396.5)$ & .02 \\
\hline \multicolumn{4}{|l|}{ ABG on lower pulmonary vein } \\
\hline $\mathrm{P} / \mathrm{F}$ ratio, $\mathrm{mm} \mathrm{Hg}$ & $59(43-259)$ & $424(278-466)$ & .01 \\
\hline Shunt fraction, $\%$ & $21.7(18.5-38.8)$ & $85.1(36.4-112.3)$ & .02 \\
\hline A-a gradient, mm Hg & $242.6(197.1-383.9)$ & $608.4(406.1-626.1)$ & .01 \\
\hline Peak inspiratory pressure, $\mathrm{cmH}_{2} \mathrm{O}$ & $21(15-30)$ & $16(14-18)$ & .06 \\
\hline Plateau pressure, $\mathrm{cmH}_{2} \mathrm{O}$ & $18(14-23)$ & $14(12-16)$ & .03 \\
\hline End tidal $\mathrm{CO}_{2}, \mathrm{~mm} \mathrm{Hg}$ & $32.5(28.0-37.0)$ & $33.5(32.0-48.0)$ & .81 \\
\hline Dynamic compliance, $\mathrm{ml} / \mathrm{cmH}_{2} \mathrm{O}$ & $17.5(8.8-30.0)$ & $29.2(25.5-34.4)$ & .06 \\
\hline Static compliance, $\mathrm{mL} / \mathrm{cmH}_{2} \mathrm{O}$ & $21.5(12.2-33.3)$ & $38.9(31.1-44.3)$ & .03 \\
\hline Pulmonary vascular resistance, dyne $\cdot \mathrm{s} / \mathrm{cm}^{5}$ & $557.6(434.3-625.0)$ & $460.6(440.0-689.7)$ & 1.00 \\
\hline
\end{tabular}

Lung weight ratio, lung weight at 2 hours of EVLP/lung weight at 0 hour of EVLP; $A B G$, Arterial blood gas analysis; $P / F$, partial pressure of arterial oxygen/fraction of inspired oxygen. Bold type shows the statistical significance of differences.

in the upper lobe pulmonary vein was not significantly different between groups (Figure 3, A). Furthermore, in the Control group, the $\mathrm{P} / \mathrm{F}$ ratio in the upper lobe was significantly greater than that in the lower lobe $(392 \mathrm{~mm}$ $\mathrm{Hg}$ [243-501 $\mathrm{mm} \mathrm{Hg}$ ] vs $59 \mathrm{~mm} \mathrm{Hg}$ [43-259 mm Hg], $P=.02$ ), whereas in the Prone group, no difference was found in $\mathrm{P} / \mathrm{F}$ ratio between the upper and lower lobes (Figure 3, A).

Lungs in the Prone group had a significantly lower shunt fraction $(36.7 \% \quad[25.2 \%-38.9 \%]$ vs $51.4 \%$ [39.6\%-60.1\%], $P=.01$ ) compared with the Control group. When evaluated by lobe, the lower lobes demonstrated significantly lower shunt fraction in the Prone group compared with the Control group (21.7\% [18.5\%-38.8\%] vs $85.1 \%$ [36.4\%-112.4\%], $P=.02$ ), whereas there was no difference between groups in upper lobe shunt fraction (Figure 3,B). The shunt fraction of the upper lobe in the Control group was significantly lower than that of the lower lobe in the Control group (25.4\% [17.3\%-27.8\%] vs $85.1 \%$ [36.4\%-112.4\%], $P=.01$ ), whereas no difference was found in the Prone Group (Figure 3, B).

Lungs in the Prone group had a significantly lower lung weight ratio (1.26 [1.24-1.41] vs 1.48 [1.36-2.34], $P=.02$ ) compared to the Control group (Table 2, Figure 3,C). Lung surface temperatures of the lower lobes in the Prone group were significantly lower compared with the Control group $\left(31.4^{\circ} \mathrm{C}\left[30.8^{\circ} \mathrm{C}-33.4^{\circ} \mathrm{C}\right]\right.$ vs $33.9^{\circ} \mathrm{C}$ $\left.\left[32.4^{\circ} \mathrm{C}-34.8^{\circ} \mathrm{C}\right], \quad P=.04\right)$, whereas there was no difference in lung surface temperature of the upper lobes (Figure 3, D). Furthermore, in the Control group, lung surface temperatures of the upper lobes were significantly lower than those of lower lobes $\left(32.1^{\circ} \mathrm{C}\left[30.5^{\circ} \mathrm{C}-32.5^{\circ} \mathrm{C}\right]\right.$ vs $33.9^{\circ} \mathrm{C}\left[32.4^{\circ} \mathrm{C}-34.8^{\circ} \mathrm{C}\right], P=.01$, Figure $\left.3, D\right)$, whereas in the Prone group, no differences were found in lung surface temperatures between the upper and lower lobes (Figure 3, D).

No significant difference was found in peak inspiratory pressure between the 2 groups $\left(16 \mathrm{cmH}_{2} \mathrm{O}\right.$ [14-18 $\left.\mathrm{cmH}_{2} \mathrm{O}\right]$ vs $21 \mathrm{cmH}_{2} \mathrm{O}$ [15-30 $\left.\mathrm{cmH}_{2} \mathrm{O}\right], P=.06$ ); however, plateau pressure and static compliance were significantly greater in the Prone group than in the Control group (plateau pressure $14 \quad \mathrm{cmH}_{2} \mathrm{O}$ [12-16 $\left.\mathrm{cmH}_{2} \mathrm{O}\right]$ vs $18 \mathrm{cmH}_{2} \mathrm{O}$ [14-23 $\left.\mathrm{cmH}_{2} \mathrm{O}\right], P=.03$; static compliance $38.9 \mathrm{~mL} / \mathrm{cmH}_{2} \mathrm{O}$ [31.1-44.3 mL/ $\left.\mathrm{cmH}_{2} \mathrm{O}\right]$ vs $21.5 \mathrm{~mL} / \mathrm{cmH}_{2} \mathrm{O}$ [12.2-33.3 mL/ $\left.\mathrm{cmH}_{2} \mathrm{O}\right], P=.03$ ). No difference was found in pulmonary vascular resistance (460.6 dyne $\cdot \mathrm{s} / \mathrm{cm}^{5} \quad\left[440.0-689.7\right.$ dyne $\left.\cdot \mathrm{s} / \mathrm{cm}^{5}\right] \quad$ vs 557.6 dyne $\cdot \mathrm{s} / \mathrm{cm}^{5}\left[434.3-625.0\right.$ dyne $\left.\left.\cdot \mathrm{s} / \mathrm{cm}^{5}\right], P>.9\right)$. In our visual findings, the 2 groups did not show a difference in the proportion of dependent atelectasis.

\section{Pathologic Findings}

Figure 4 shows the ALI grade difference in lower lobes. One hundred percent of lungs in the Prone group had no grade change (ALI grade difference 0 ) or minus number 

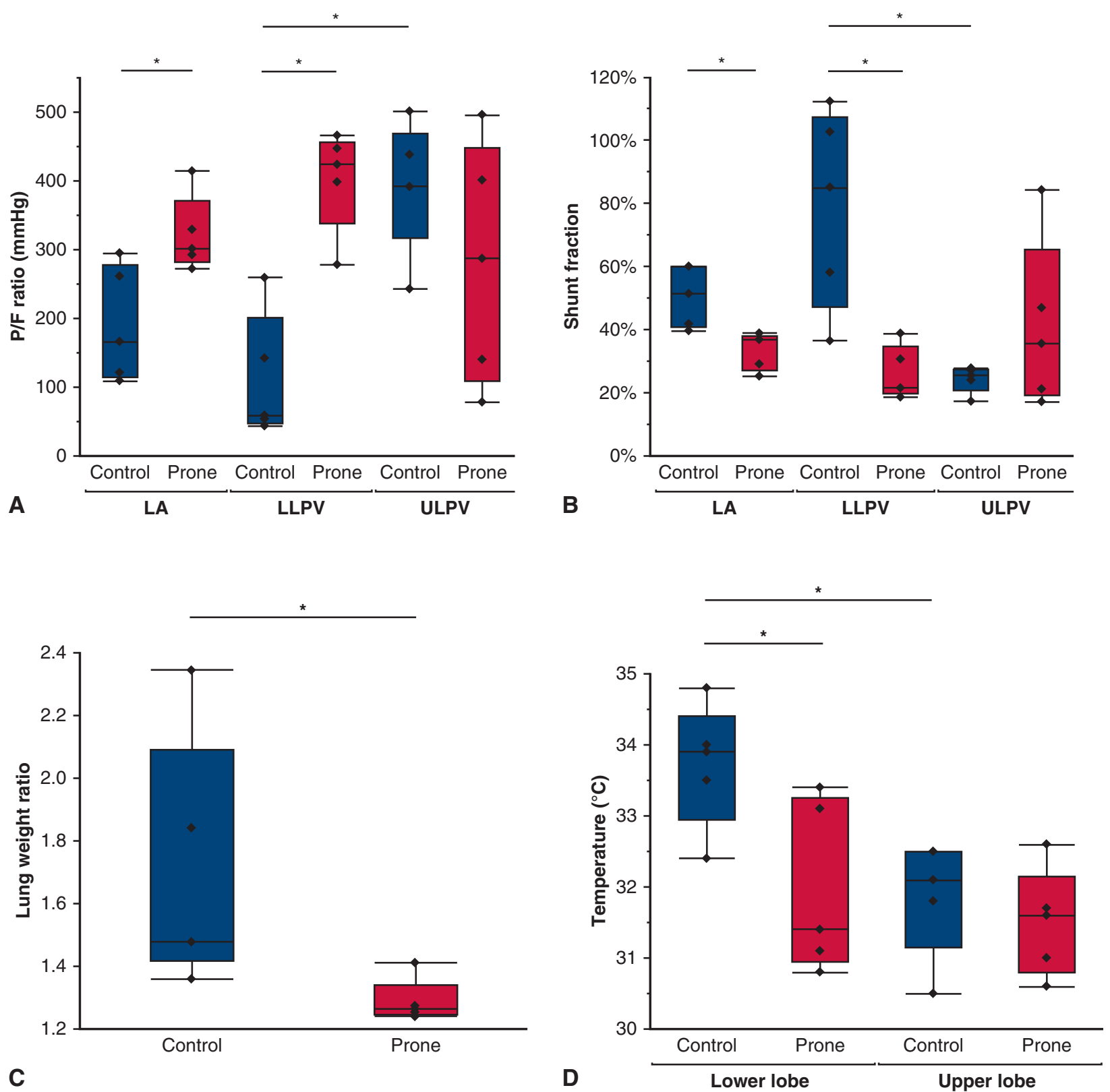

FIGURE 3. Physiological characteristics of Control and Prone groups during EVLP represented by box and whiskers plots. The middle horizontal line represents the median, and the upper and lower whiskers represent the maximum and minimum values. Each box represents the middle $50 \%$ of the data ( $25 \%-75 \%$ range). A, P/F ratio, comparing the Control group and Prone group for 3 blood gas sampling points. The P/F ratios of the lower lobe (P/F ratio in LLPV) were compared with those of the upper lobe (P/F ratio in ULPV) in each of the Control and Prone groups. $* P<.05$. B, Shunt fraction, comparing the Control and Prone groups for 3 points. The shunt fractions of the lower lobe were compared with those of the upper lobe in each of the Control and Prone groups. $* P<.05$. C, Lung weight ratio, defined as lung weight at 2 hours/lung weight at 0 hour, comparing the 2 groups. $* P<.05$. D, Lung surface temperature, comparing the Control and Prone groups for each lobe. ${ }^{*} P<.05 . P / F$, Partial pressure of arterial oxygen/fraction of inspired oxygen; $L A$, left atrium; $L L P V$, lower lobe pulmonary vein; $U L P V$, upper lobe pulmonary vein.

(ALI grade difference -1 ) from 0 to 2 hours of EVLP, whereas $60 \%$ of lungs in the Control group demonstrated an increase of ALI grade (ALI grade difference 1), even though the 2 groups did not show a significant difference using a Fisher exact test $(P=.17)$.

\section{Cytokine Tissue Analysis}

IL-1 $\beta$ level in the lower lobe of the Prone group was significantly lower than that in the Control group $(1.6 \mathrm{ng} / \mathrm{mL} \quad[0.9-5.3 \mathrm{ng} / \mathrm{mL}]$ vs $7.5 \mathrm{ng} / \mathrm{mL}$ $[5.0-16.1 \mathrm{ng} / \mathrm{mL}], P=.04$, Figure $5, A)$. In the Prone group, 


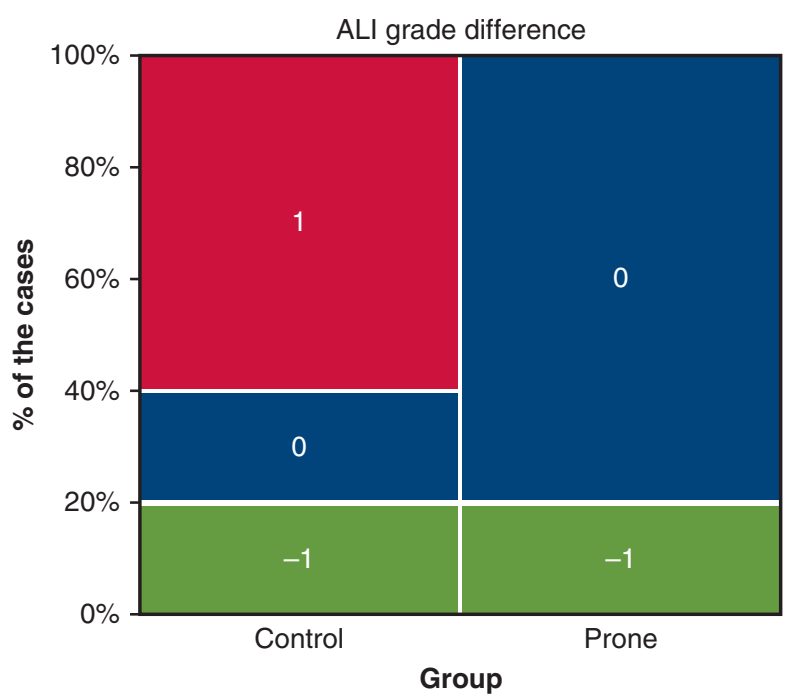

FIGURE 4. Pathologic findings of lower lobes in the Control and Prone groups before and after EVLP. Mosaic plot showing the percentage of cases with $A L I$ grade difference between 2 and 0 hours of EVLP in the lower lobes. The number in each box shows the ALI grade difference. All of the cases in the Prone group showed no grade change (ALI grade difference 0 ) or a decrease in grade (ALI grade difference -1), but no statistical significance was found between the 2 groups using Fisher exact test $(P=.17)$.

IL- $1 \beta$ in the lower lobe was significantly lower than that in the upper lobe $(1.6 \mathrm{ng} / \mathrm{mL}[0.9-5.3 \mathrm{ng} / \mathrm{mL}]$ vs $10.2 \mathrm{ng} / \mathrm{mL}$ [5.6-13.7 ng/mL], $P=.01$, Figure 5, $A$ ).

IL-8 level in the lower lobe of the Prone group was significantly lower than that in the Control group $(0.28 \mathrm{ng} / \mathrm{mL} \quad[0.21-0.41 \quad \mathrm{ng} / \mathrm{mL}] \quad$ vs $0.48 \quad \mathrm{ng} / \mathrm{mL}$ $[0.30-0.61 \mathrm{ng} / \mathrm{mL}], P=.04$, Figure $5, B$ ). In the Prone group, the IL-8 level in the lower lobe was significantly lower than that in the upper lobe $(0.28 \mathrm{ng} / \mathrm{mL}$ [0.21- $0.41 \mathrm{ng} / \mathrm{mL}]$ vs $0.49 \mathrm{ng} / \mathrm{mL}[0.37-0.69 \mathrm{ng} / \mathrm{mL}], P=.04$, Figure $5, B)$.

In addition, IL-10 level in the lower lobe of the Prone group was greater (not significantly) than that in the Control group $(17.8 \mathrm{pg} / \mathrm{mL}[2.8-29.5 \mathrm{pg} / \mathrm{mL}]$ vs $7.7 \mathrm{pg} / \mathrm{mL}$ [2.8-10.1 pg/mL], $P=.09$, Figure 5, C). In the Prone group, IL-10 level in the lower lobe was higher (not significantly) than that in the upper $(17.8 \mathrm{ng} / \mathrm{mL}$ [2.8-29.5 $\mathrm{ng} / \mathrm{mL}] \mathrm{vs}$ $7.7 \mathrm{ng} / \mathrm{mL}[1.7-25.6 \mathrm{ng} / \mathrm{mL}], P=.30$, Figure $5, C$ ).

\section{DISCUSSION}

The most important finding in our study was that in this rigorous model of warm lung ischemia followed by cold preservation the degree of ischemic reperfusion injury (IRI) was significantly lower and lung function was significantly better when lungs were perfused in a prone position during cellular EVLP. In IRI, inflammation and enhanced vascular permeability leads to pulmonary edema and tissue injury. Clinically, this is manifest as poor oxygenation, infiltrates demonstrable on chest radiograph, and poor pulmonary compliance. ${ }^{17}$ In our study, lungs in the Prone group had a significantly greater $\mathrm{P} / \mathrm{F}$ ratio, lower shunt fraction, and lower lung weight ratio compared with the Control group (Figure 3, A-D, Graphical Abstract).

In addition, both the ALI grade and inflammatory cytokine expression were diminished in lower lobes of the Prone group compared with the Control group (Figure 5) at 2 hours of EVLP. These results indicate that prone positioning of lungs during cellular EVLP may reduce the degree of IRI and result in better lung function.

In our model, there was differential expression of tissue cytokines in the upper and lower lobes that was dependent on lung position during EVLP. The expression of IL- $1 \beta$ and IL-8 in lower lobe tissue in the Prone group was less than that in the Control group. In addition, the expression of IL-10, an anti-inflammatory cytokine, was greater in lower lobe tissue in the Prone group. In contrast, IL- $1 \beta$ expression in the upper lobe tissue of the Prone group was greater than that in the Control group whereas IL-8 and IL-10 levels were not significantly different. These data suggest that the positional change of the lungs in the Prone group resulted in significantly less inflammation and tissue injury in the lower lobes whereas inflammation (as demonstrated by IL- $1 \beta$ levels) increased slightly in the upper lobes. However, the lung weight ratio of whole lungs in the Prone group was significantly less that in the Control group, demonstrating that lungs accumulated less water during EVLP. In total, these data demonstrate that the protective effect of prone positioning on the lower lobes was greater than any detrimental effect on the upper lobes resulting in improved overall lung function.

The anatomical position of the lung lobes, in addition to the gravitational effect, might explain these findings. In prone position, the upper lobe is relatively more dependent than the lower lobe, and this results in causing it to be more susceptible to gravitational effect than in the supine position. In contrast, the upper lobe is relatively less dependent than the lower lobe in the supine position. This less-dependent position may result in an appropriate V/Q matching and better-preserved lung function in the upper lobes in supine position and the lower lobes in prone position. On the contrary, the more dependent position may cause more injury to the upper lobes in prone position and the lower lobes in supine position. However, according to our results, there is less injury caused to the upper lobes in prone position than to the lower lobes in supine position. Therefore, the overall function of the lungs in prone position is better than in supine position.

It would be worth discussing whether increasing PEEP or potentially increasing TV could alleviate the differences observed between oxygenation and shunt fraction. In the EVLP setting, with the absence of the chest wall, we think that increasing the PEEP or TV might cause hyperinflation and injury to the already-inflated regions of the lungs rather 

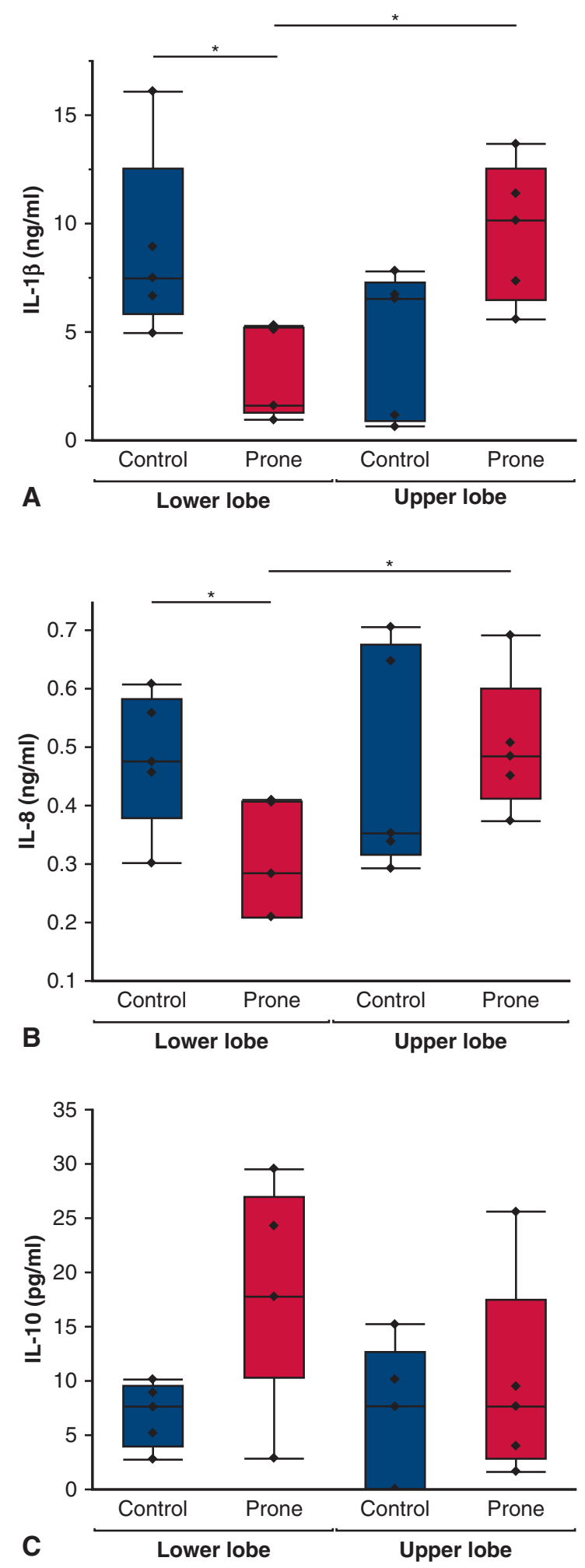

FIGURE 5. Inflammatory cytokines levels in the tissue samples of Control and Prone groups at the end of EVLP are represented by box and whiskers plots. The middle horizontal line represents the median, and the upper and lower whiskers represent the maximum and minimum values. Each box represents the middle $50 \%$ of the data (25\%-75\% range). than opening the collapsed regions. The increased opening pressure of the collapsed regions of the lung and the lower resistance in the inflated regions of the lungs compared to the collapsed regions supports our theory. In addition, the absence of the resistance of the chest wall plays a crucial role in limiting the beneficial effects of increasing PEEP or TV in positive pressure ventilation in EVLP setting.

In our study, we measured lung surface temperature using thermography of both the upper and lower lobes as a surrogate of lung lobar flow, as demonstrated by Motoyama and colleagues ${ }^{18}$ As shown in Figure 3, D, the average temperature of the lower lobe in the Prone group was significantly less than that in the Control group. In contrast, there was no difference between the 2 groups in the lung surface temperature of upper lobes. We postulate that this alteration in flow to the lower lobes may have provided some protection from IRI. This protective effect perhaps in conjunction with improvement in V/Q matching may have contributed to the improved lung function in prone positioned lungs as reflected by the significantly better $\mathrm{P} / \mathrm{F}$ ratio, lower shunt fraction and lower A-a gradient. These findings are consistent with the effects of prone positioning in patients in the ICU with severe pulmonary disease $^{5}$ and are also consistent with a report by Richard and colleagues ${ }^{6}$ in the pig model with ALI that changing from supine position to prone position improved V/Q matching.

We used this model of cellular EVLP to assess the effect of prone positioning on lung function/injury during perfusion because cellular EVLP is a common mode of EVLP used by several perfusion systems. Whether similar results would be found in an acellular perfusion system is unclear and should be investigated. Our data do suggest, however, that, consistent with human ICU data, alteration of lung position during perfusion may improve lung function and diminish lung injury. The function of perfused lungs treated in such a fashion should be evaluated in a transplant model. Furthermore, to test the applicability of our results in the clinical setting, a human model study using human donor lungs should be considered. The results could prove the feasibility of this technique in the clinical setting.

This study has several limitations. First, the animal model in this study may be different from human donor lungs due to the absence of brain death and pulmonary edema in the pig model. There is a minor difference in the shape of pig lungs between pig and human. We should note that that our current results of this porcine model may not

Three cytokines were compared between the Control group and Prone group in each lobe. Three cytokines of the lower lobe were also compared with those in the upper lobe of the Control and Prone groups. A, IL-1 $\beta$, (B) IL-8, (C) IL-10. *P<.05. IL, Interleukin. 
extrapolate directly to humans. Second, the case numbers of 2 study groups were limited. The results of this study may represent type II statistical error, a function of the small sample size. Third, there is a difference in standing position between human and pigs. Generally speaking, patients are positioned in a supine, whereas pigs stand in a prone position.

In conclusion, this study demonstrated that prone positioning during EVLP was significantly associated with less lung weight gain, better $\mathrm{P} / \mathrm{F}$ ratio and improved compliance, lower inflammatory cytokines, and lower ALI grade difference than supine positioning in the Control group. These data indicate that prone position of porcine lungs may diminish IRI during EVLP, suggesting that prone position of lungs during EVLP might be a therapeutic option to improve pulmonary function in clinical EVLP practice.

\section{Conflict of Interest Statement}

Authors have nothing to disclose with regard to commercial support.

We express our deepest gratitude to Vivoline Medical, Inc, for Vivoline LS1, and Maquet for the support of Servo-i ventilator. We are also grateful to Lucy Thuita for supervisor of statistical analysis, Amanda Mendelsohn for illustration, and Dr Tracey Bonfield for cytokine analysis.

\section{References}

1. Gattinoni L, Tognoni G, Pesenti A, Taccone P, Mascheroni D, Labarta V, et al. Effect of prone positioning on the survival of patients with acute respiratory failure. N Engl J Med. 2001;345:568-73.

2. Bloomfield R, Noble DW, Sudlow A. Prone position for acute respiratory failure in adults. Cochrane Database Syst Rev 2015;11:CD008095.

3. Gattinoni L, Pesenti A, Carlesso E. Body position changes redistribute lung computed-tomographic density in patients with acute respiratory failure: impact and clinical fallout through the following 20 years. Intensive Care Med. 2013;39: 1909-15.

4. Gattinoni L, Taccone P, Carlesso E, Marini JJ. Prone position in acute respiratory distress syndrome. Rationale, indications, and limits. Am J Respir Crit Care Med. 2013;188:1286-93.
5. Kallet RH. A comprehensive review of prone position in ARDS. Respir Care. 2015;60:1660-87.

6. Richard JC, Bregeon F, Costes N, Bars DL, Tourvieille C, Lavenne F, et al. Effects of prone position and positive end-expiratory pressure on lung perfusion and ventilation. Crit Care Med. 2008;36:2373-80.

7. Steen S, Sjoberg T, Pierre L, Liao Q, Eriksson L, Algotsson L. Transplantation of lungs from a non-heart-beating donor. Lancet. 2001;357:825-9.

8. Steen S, Ingemansson R, Eriksson L, Pierre L, Algotsson L, Wierup P, et al. First human transplantation of a nonacceptable donor lung after reconditioning ex vivo. Ann Thorac Surg. 2007;83:2191-4.

9. Cypel M, Yeung JC, Liu M, Anraku M, Chen F, Karolak W, et al. Normothermic ex vivo lung perfusion in clinical lung transplantation. N Engl J Med. 2011;364: 1431-40.

10. Wallinder A, Riise GC, Ricksten S-E, Silverborn M, Dellgren G. Transplantation after ex vivo lung perfusion: a midterm follow-up. J Heart Lung Transplant. 2016;35:1303-10.

11. Nakajima D, Cypel M, Bonato R, Machuca TN, Iskender I, Hashimoto K, et al. Ex vivo perfusion treatment of infection in human donor lungs. Am J Transplant. 2016;16:1229-37.

12. Cypel M, Liu M, Rubacha M, Yeung JC, Hirayama S, Anraku M, et al Functional repair of human donor lungs by IL-10 gene therapy. Sci Transl Med. 2009;1:4ra9.

13. Chan M-C, Hsu J-Y, Liu H-H, Lee Y-L, Pong S-C, Chang L-Y, et al Effects of prone position on inflammatory markers in patients with ARDS due to community-acquired pneumonia. J Formo Med Assoc. 2007;106: 708-16.

14. Okamoto T, Wheeler D, Liu Q, Quintini C, Hata JS, McCurry KR. Variability in pressure of arterial oxygen to fractional inspired oxygen concentration ratio during cellular ex vivo lung perfusion: implication for decision making Transplantation. 2015;99:2504-13.

15. Okamoto T, Wheeler D, Liu Q, Quintini C, Hata JS, McCurry KR. Correlation between $\mathrm{PaO} 2 / \mathrm{FiO} 2$ and airway and vascular parameters in the assessment of cellular ex vivo lung perfusion system. J Heart Lung Transplant. 2016;35:1330-6.

16. Okamoto T, Wheeler D, Chakravarti R, Liu Q, Janocha A, Laskowski D, et al. Treatment with sodium nitrite improves the pulmonary function of rejected human lungs in cellular ex vivo lung perfusion model. J Heart Lung Transplant. 2015;34:S139.

17. de Perrot M, Liu M, Waddell TK, Keshavjee S. Ischemia-reperfusion-induced lung injury. Am J Respir Crit Care Med. 2003;167:490-511.

18. Motoyama H, Chen F, Hijiya K, Kondo T, Ohata K, Takahashi M, et al Novel thermographic detection of regional malperfusion caused by a thrombosis during ex vivo lung perfusion. Interact Cardiovasc Thorac Surg. 2015;20:242-7.

Key Words: prone positioning, ex vivo lung perfusion, ischemia-reperfusion injury, lung transplantation, lung function assessment 